\title{
Approaches of Genetic Regulation in Actinomycetes for Antibiotic Synthesis
}

\author{
Chunli Liao ${ }^{1}, X_{\text {Xiaobo Liu }}^{1,2^{*}}$ and Linna Shan ${ }^{1 *}$ \\ ${ }^{1}$ College of Life Science and Engineering, Henan University of Urban Construction, Pingdingshan 467036, Henan, China \\ ${ }^{2}$ School of Biological Sciences, The University of Hong Kong, Hong Kong
}

"Corresponding authors: Xiaobo Liu, College of Life Science and Engineering, Henan University of Urban Construction, Henan, China, Tel: 8603752089090; Fax: 8603752089090; E-mail: bolieyliu@hotmail.com

Received date: December 22, 2015; Accepted date: December 27, 2015; Published date: December 31, 2015

Copyright: (c) 2015 Liao C, et al. This is an open-access article distributed under the terms of the Creative Commons Attribution License, which permits unrestricted use, distribution, and reproduction in any medium, provided the original author and source are credited.

\section{Description}

Microorganisms, especially actinomycetes, can generate a wide variety of bioactive secondary metabolites [1]. The majority of these metabolites have positive effects on antibiosis, anti-tumor, pesticide, immunosuppression and immune activation, and they therefore have been widely applied in medicine, agriculture and food industry [2]. With the appearance of drug-resistance bacteria, many researches today are focusing on how to improve the biosynthesis of antibiotic in actinomycetes and how to exploit new antibiotics [3]. However, the most effective way to achieve this is by regulating the process of secondary metabolism in genetic levels $[4,5]$. Therefore, this overview will summarize current approaches of genetic regulation in the antibiotic synthesis of actinomycetes.

\section{Regulation of Expression of Regulatory Genes}

The genes responsible for antibiotic biosynthesis generally exist as a cluster in actinomycetes [6]. In addition to structural genes, these gene clusters usually contain regulatory genes, resistance genes against corresponding antibiotics and transport genes [7]. And the antibiotic biosynthesis is therefore simultaneously controlled by these resistance genes, regulatory genes and transport genes [8]. However, the transcription of gene clusters relies mainly on the regulations of general or specific regulatory proteins $[9,10]$. Generally, specific regulatory genes exist in the cluster relating to the biosynthesis of secondary metabolites, like Streptomycetes antibiotic regulatory protein (SARP) [10,11]. Also, the specific regulation involves the positive regulation and negative regulation [8]. Therefore, the biosynthesis can be increased by over-expressing the positive regulatory genes and knocking off the negative regulatory genes.

\section{Regulation of expression of Gene Clusters}

Two approaches contribute to this regulation. One is to increase the number of copies of gene clusters responsible for antibiotic biosynthesis [12]. This means that increasing the copies of gene clusters can directly manage to improve the biosynthesis when the relevant gene clusters have already been known [12-14]. However, this method has its shortage that the increase of production is limited because of the influences from other genetic regulations. Moreover, the other approach is by controlling the heterogeneous expression of gene clusters relating to antibiotic synthesis $[15,16]$. There are a huge variety of actinomycetes in the nature, but only $10 \%$ of them have been exploited for antibiotic production [17,18]. Genome mining could recognize gene clusters relating to antibiotic biosynthesis via bioinformatic technology and then activate the relevant gene clusters through genetic engineering [19]. Combining with genome mining, the heterogeneous expression could come true by introducing a wide range of wild-type genes. Therefore, it is also an effective approach to develop new antibiotics.

\section{Regulation of Expression of Resistance Genes}

Resistance genes determine the level of antibiotic resistance in actinomycetes [19]. Resistance proteins will inhibit the expression of relevant genes and subsequently prevent the biosyntheisis of antibiotic if the majority of resistance proteins react with antibiotics resulting in the concentration of antibiotic exceeding the resistance of cell [20]. Therefore, improving the expression of resistance genes or the tolerance to antibiotic in actinomycetes can increase the biosyntheisis of antibiotic [18].

\section{Regulation of Expression of Transport Genes}

It is well reported that both growth and metabolism of cells will be inhibited if the concentration of intracellular antibiotics reach beyond the level of resistance of cells [21]. Therefore, pumping out antibiotics timely from cells and maintaining antibiotics at the normal concentration can greatly increase their biosynthesis in actinomycetes [22]. However, transport proteins play a key role in this process. Accordingly, we can then improve the biosynthesis through the expression of relevant transport genes.

\section{Regulation of Expression of Ribosome-related Proteins}

By now, it is reported that three main synthetic pathways, namely PKS, NRPS and RiPPs, contribute to the biosynthesis of antibiotic $[23,24]$. Among them, RiPPs must be completed in the ribosome and therefore some ribosome-related proteins would have effects on the biosynthesis of antibiotic. Ribosome recycling factor (RRF) is the protein that takes charge of dissociating the relevant RNA from ribosome when the transcription is completed $[25,26]$. For instance, over-expressing the gene frr in Streptomyces diastatochromo-genes 1628 has managed to increase the production of antibiotic [27,28]. RimP-SC is an assembly protein in ribosome, and knocking off this RimP-SC gene could increase the biosynthesis of antibiotic Act and CDA in Streptomyces coelicolor [29]. Likewise, in Streptomyces venezuelae, the biosynthesis of jadomycin could be improved by knocking off RimP-SV genes [30].

There are many unknown gene clusters that take responsibility for the biosynthesis of secondary metabolites in actinomycetes. However, these gene clusters usually have low expression or even no expression in trial. Also, many valuable secondary metabolites than can be used as 
the source of new drugs exist in actinomycetes. With the development of bioinformatics, researches on antibiotics will emphasize on how to explore and recognize secondary-metabolite-related gene clusters, then how to transform and assemble the recognized clusters via DNA engineering, and finally how to heterologously express and activate these clusters. Besides, the metabolic regulation is also an effective approach to improve the biosynthesis of antibiotic in actinomycetes. In summary, genetic regulation would have more potential and promise in the improvement and development of antibiotic industry.

\section{Acknowledgement}

We gratefully acknowledge the financial support by the Henan Key Science and Technology Research (Grant No.092102310069), and project research of Henan University of Urban Construction (Grant No. 2015JZDXK001).

\section{References}

1. Chen W, Qi J, Wu P, Wan D, Liu J, et al. (2015) Natural and engineered biosynthesis of nucleoside antibiotics in Actinomycetes. J Ind Microbiol Biotechnol 1-17.

2. Alexander DC, Rock J, Gu JQ, Mascio C, Chu M, et al. (2011) Production of novel lipopeptide antibiotics related to A54145 by Streptomyces fradiae mutants blocked in biosynthesis of modified amino acids and assignment of lptJ, lptK and lptL gene functions. J Antibiot (Tokyo) 64: 79-87.

3. Fankam AG, Kuiate JR, Kuete V (2015) Antibacterial and antibiotic resistance modifying activity of the extracts from allanblackia gabonensis, combretum molle and gladiolus quartinianus against Gram-negative bacteria including multi-drug resistant phenotypes. BMC Complement Altern Med 15: 206.

4. Adamidis T, Champness W (1992) Genetic analysis of absB, a Streptomyces coelicolor locus involved in global antibiotic regulation. J Bacteriol 174: $4622-4628$.

5. Novakova R, Rehakova A, Feckova L, Kutas P, Knischova R, et al. (2011) Genetic manipulation of pathway regulation for overproduction of angucycline-like antibiotic auricin in Streptomyces aureofaciens CCM 3239. Folia Microbiol (Praha) 56: 276-282.

6. Chater KF, Bruton CJ (1985) Resistance, regulatory and production genes for the antibiotic methylenomycin are clustered. EMBO J 4: 1893-1897.

7. Fernandez-Moreno MA, Caballero JL, Hopwood DA, Malpartida F (1991) The act cluster contains regulatory and antibiotic export genes, direct targets for translational control by the bldA tRNA gene of Streptomyces. Cell 66: 769-780.

8. Sekurova ON, Brautaset T, Sletta H, Borgos SE, Jakobsen M, et al. (2004) In vivo analysis of the regulatory genes in the nystatin biosynthetic gene cluster of Streptomyces noursei ATCC 11455 reveals their differential control over antibiotic biosynthesis. J Bacteriol 186: 1345-1354.

9. Makitrynskyy R, Ostash B, Tsypik O, Rebets Y, Doud E, et al. (2013) Pleiotropic regulatory genes bldA, adpA and absB are implicated in production of phosphoglycolipid antibiotic moenomycin. Open Biol 3: 130121.

10. Zhang B, Yang D, Yan Y, Pan G, Xiang W, et al. (2015) Overproduction of lactimidomycin by cross-overexpression of genes encoding Streptomyces antibiotic regulatory proteins. Appl Microbiol Biotechnol.

11. Rebets Y, Dutko L, Ostash B, Luzhetskyy A, Kulachkovskyy O, et al. (2008) Function of lanI in regulation of landomycin A biosynthesis in Streptomyces cyanogenus S136 and cross-complementation studies with Streptomyces antibiotic regulatory proteins encoding genes. Arch Microbiol 189: 111-120
12. Li H, Zhao C, Chen H, Zhang F, He W, Wang X, et al. (2013) Identification of gene clusters associated with host adaptation and antibiotic resistance in Chinese Staphylococcus aureus isolates by microarray-based comparative genomics. PLoS One 8: e53341.

13. Arakawa K (2014) Genetic and biochemical analysis of the antibiotic biosynthetic gene clusters on the Streptomyces linear plasmid. Biosci Biotechnol Biochem 78: 183-189.

14. Hochhut B, Lotfi Y, Mazel D, Faruque SM, Woodgate R, et al. (2001) Molecular analysis of antibiotic resistance gene clusters in vibrio cholerae O139 and O1 SXT constins. Antimicrob Agents Chemother 45: 2991-3000.

15. Ploy MC, Lambert T, Couty JP, Denis F (2000) Integrons: an antibiotic resistance gene capture and expression system. Clin Chem Lab Med 38: 483-487.

16. Motamedi H, Hutchinson CR (1987) Cloning and heterologous expression of a gene cluster for the biosynthesis of tetracenomycin C, the anthracycline antitumor antibiotic of Streptomyces glaucescens. Proc Natl Acad Sci USA 84: $4445-4449$.

17. Sugiyama M (2015) Structural biological study of self-resistance determinants in antibiotic-producing actinomycetes. J Antibiot (Tokyo) 68: 543-550.

18. Weber T, Charusanti P, Musiol-Kroll EM, Jiang X, Tong Y, et al. (2015) Metabolic engineering of antibiotic factories: new tools for antibiotic production in actinomycetes. Trends Biotechnol 33: 15-26.

19. Tang X, Li J, Millán-Aguiñaga N, Zhang JJ, O'Neill EC, et al. (2015) Identification of Thiotetronic Acid Antibiotic Biosynthetic Pathways by Target-directed Genome Mining. ACS Chem Biol 10: 2841-2849.

20. Torbochkina LI (1970) Molecular mechanism of inhibition of biosynthesis of peptidoglycan of bacterial cell walls by antibiotics. Antibiotiki 15: 465-476.

21. Wang Y, Venter H, Ma S (2015) Efflux Pump Inhibitors: A Novel Approach to Combat Efflux-Mediated Drug Resistance in Bacteria. Curr Drug Targets.

22. Walsh CT, Fischbach MA (2008) Inhibitors of sterol biosynthesis as Staphylococcus aureus antibiotics. Angew Chem Int Ed Engl 47: 5700-5702.

23. Tokhtamuratov E, Sulaev AB (1967) Study of conditions for biosynthesis of tetraenic antibiotics 18-45 and 18-80, heptaenic antibiotic 2368. Antibiotiki 12: 887-892.

24. Voronina OI, Khokhlov A (1972) Pathways of biosynthesis of peptide moieties of streptothricin antibiotics. Postepy Hig Med Dosw 26: 541-548.

25. Kaji A, Hirokawa G, Atarashi K (1999) Ribosome recycling factor (RRF): a factor which disassemble the post-termination complex and reduces translational error. Tanpakushitsu Kakusan Koso 44: 831-844.

26. Janosi L, Hara H, Zhang S, Kaji A (1996) Ribosome recycling by ribosome recycling factor (RRF)--an important but overlooked step of protein biosynthesis. Adv Biophys 32: 121-201.

27. Ndlovu TM, Ward AC, Glassey J, Eskildsen J, Akay G (2015) Bioprocess intensification of antibiotic production by Streptomyces coelicolor A3(2) in micro-porous culture. Mater Sci Eng C Mater Biol Appl 49: 799-806.

28. Zhang P, Zhao Z, Li H, Chen XL, Deng Z, et al. (2015) Production of the antibiotic FR-008/candicidin in Streptomyces sp. FR-008 is co-regulated by two regulators, FscRI and FscRIV, from different transcription factor families. Microbiology 161: 539-552.

29. Ma Z, Tao L, Bechthold A, Shentu X, Bian Y, et al. (2014) Overexpression of ribosome recycling factor is responsible for improvement of nucleotide antibiotic-toyocamycin in Streptomyces diastatochromogenes 1628. Appl Microbiol Biotechnol 98: 5051-5058.

30. Pan Y, Lu C, Dong H, Yu L, Liu G, et al. (2013) Disruption of rimP-SC, encoding a ribosome assembly cofactor, markedly enhances the production of several antibiotics in Streptomyces coelicolor. Microb Cell Fact 12: 65. 